\title{
Research Square \\ Kinetic Study of Liquid Lipase-catalyzed Glycerolysis From Olive Oil Using Lipozyme TL 100L
}

José Vladimir Oliveira ( $\nabla$ jose.vladimir@ufsc.br)

Universidade Federal de Santa Catarina https://orcid.org/0000-0002-6196-3498

George F. Finco

UNIOESTE: Universidade Estadual do Oeste do Parana

Karina G. Fiametti

UNIOESTE: Universidade Estadual do Oeste do Parana

Edson A. da Silva

UNIOESTE: Universidade Estadual do Oeste do Parana

Fernando Palú

UNIOESTE: Universidade Estadual do Oeste do Parana

João H. C. Wancura

UFSM: Universidade Federal de Santa Maria

Alexsandra Valério

UFSC: Universidade Federal de Santa Catarina

\section{Research Article}

Keywords: Monoacylglycerol, diacylglycerol Lipase, Surfactant, Statistical Design, Kinetic Modeling

Posted Date: March 10th, 2021

DOl: https://doi.org/10.21203/rs.3.rs-275118/v1

License: (c) (i) This work is licensed under a Creative Commons Attribution 4.0 International License.

Read Full License 
3

12

13

14

15

16

17 João H. C. Wancura: jhwancura@mail.ufsm.br

18 Alexsandra Valério: ale valerio1@ yahoo.com.br

19

20

21

\section{Authors e-mails:}

Karina G. Fiametti: karinafiametti@utfpr.edu.br

Edson A. da Silva: edsondeq@hotmail.com

Fernando Palú: fernando.palu@unioeste.br

J. Vladimir Oliveira: jose.vladimir@ufsc.br
Kinetic study of liquid lipase-catalyzed glycerolysis from olive oil using

\section{Lipozyme TL 100L}

${ }^{a}$ Department of Chemical and Food Engineering, Federal University of Santa Catarina, Florianópolis, SC, Brazil

${ }^{b}$ Department of Chemical Engineering, Western State University of Paraná, Toledo, PR, Brazil

${ }^{c}$ Department of Chemical Engineering, Federal Technological University of Paraná, Toledo, PR, Brazil

${ }^{d}$ Department of Chemical Engineering, Federal University of Santa Maria, Santa Maria, RS, Brazil

George F. Finco: georgefernando.f@hotmail.com

\footnotetext{
${ }^{*}$ Corresponding author: jose.vladimir@ ufsc.br (J. Vladimir de Oliveira). ORCID: 0000-0002-6196-3498.
} 


\section{Abstract}

23 Monoacylglycerol (MAG) and diacylglycerol (DAG) are two natural components found in most

24 edible oils and fats. Conventional synthesis of MAG and DAG is usually conducted by glycerolysis 25 of triacylglycerol (TAG) at high temperatures (above $200{ }^{\circ} \mathrm{C}$ ) in the presence of an alkaline 26 catalyst. In this work, the synthesis of MAG and DAG using enzymatic glycerolysis of olive oil 27 was investigated using Tween 80 as surfactant, $n$-butanol as co-surfactant and the novel lipase in 28 liquid formulation Lipozyme TL 100L as catalyst. Experimental design was used to evaluate the 29 effect of enzyme load and reaction temperature on the feedstock conversion. Enzyme load and 30 system temperature were significant variables in the statistical design and the best condition was 31 found at $35{ }^{\circ} \mathrm{C}, 7.5$ vol\% of Lipozyme TL 100 and 2:1 molar ratio (glycerolysis:oil) with 32 conversion of TAG at approximately $98 \%$ after $2 \mathrm{~h}$ of process. A mathematical model based on 33 the Ping-Pong Bi-Bi mechanism was used to describe the reaction kinetics. The model adequately 34 described the behavior of the system and can be a useful tool for the design of reactors in larger 35 scales.

\section{Keywords}

38 Monoacylglycerol; diacylglycerol Lipase; Surfactant; Statistical Design; Kinetic Modeling. 


\section{Introduction}

Monoacylglycerols (MAGs) are esters formed by fatty acids/glycerol largely utilized on

42 industrial demands due its stabilizing, emollient and binding properties. This compound was

43 approved by the Food and Drug Administration (FDA, United States) for use as emulsifiers in food

44 and pharmaceuticals applications for not presenting collateral effects when ingested [1]. Within

45 this same reasoning, diacylglycerols (DAGs) act in the treatment of cholesterol, prevention of

46 obesity and reduction of body fat accumulation, bringing beneficial for reducing diseases related

47 to such health problems.

48 The synthesis of MAG and DAG is performed in distinct ways. The conventional technique applied industrially occurs by triacylglycerols (TAGs) glycerolysis, usually at high temperatures

50 (above $200{ }^{\circ} \mathrm{C}$ ) in the presence of chemical (alkaline) catalyst. Under these conditions, a mixture composed around of $50 \mathrm{wt} \%$ of MAG, $40 \mathrm{wt} \%$ of DAG and $10 \mathrm{wt} \%$ of TAG is obtained [2, 3]. On

52 the other hand, although it is still a scarcely explored topic, researches published recently highlight

53 the potential of the use of lipases as biocatalysts on glycerolysis due to the reaction works at mild

54 reaction conditions, implying a low energy demand of the process and by high selectivity of the 55 enzymes, allowing a higher amount of product synthesis [4, 5].

In the enzymatic glycerolysis, an important point that should be mentioned is the presence

57 of glycerol in the system. Frequently, the glycerol can bound with the enzyme and forming an 58 inactive complex with the glycerol reducing the reaction efficiency once the glycerol is a 59 competitive inhibitor [6]. Thus, ensure the system homogeneity is a crucial factor during the lipase60 catalyzed glycerolysis. To aid this point, the use of a surfactant may promote higher homogeneity

61 for the system oil-glycerol-enzyme, increasing the interfacial area, improving the immiscibility 62 between the substrates, providing higher reaction rates and enhancing the biocatalyst efficiency, 
mainly for lipases which are characterized as acting at the interface $[4,5,7,8]$. There are two requirements for enzyme glycerolysis to occur: firstly, the oil-glycerol interface is formed; and then the enzyme is adsorbed in that system. Thus, the higher the interface, the higher the amount of enzyme adsorbed, which implies in lower activation energies and, consequently, higher reaction rates [9]. For this, the area of contact between enzymes and substrate is increased with the use of micelles. The micelles provide higher glycerol miscibility on apolar solvents, through the physicochemical characteristics of the micellar system and the interaction with the surface area where TAG break down and form MAG and DAG [10].

The majority of studies that address enzymatic glycerolysis to obtain MAG and DAG use immobilized lipases as reaction catalyst $[11,12]$. The use of lipases in liquid formulations, as the novel Lipozyme TL 100L recently launched by Novozymes $\mathrm{A} / \mathrm{S}$, can be observed in scarce researches [13-15]. These papers evaluated only factors of process such as molar ratio of the system, the source and type of the enzyme activation. Furthermore, kinetic parameters estimation for this process are rare in the literature. However, mathematical modeling and knowledge of reaction kinetics are fundamental in reactors design. After all, modeling is used for the processes analysis to define strategies of operation, optimization and system control. Therefore, it is necessary to use representative, fast computing models with the good mapping of the variables and cause-effect in the processes [16]. Consequently, it is required to know the reaction kinetics to be able to reconcile the complexity of the chosen model and to better represent the reactor with the variables available and proposed $[17,18]$.

This work presents experimental results of the kinetics of enzymatic glycerolysis of olive oil in a batch reactor, using Tween 80 as surfactant, $n$-butanol as co-surfactant and the liquid lipase Lipozyme TL 100L, to evaluate the effect of temperature and enzyme concentration in the feedstock conversion. Moreover, a complete mathematical model considering the glycerolysis and 
87 hydrolysis of the raw material to describe the process is also presented.

$89 \quad$ Materials and Methods

90

\section{Materials}

Refined olive oil (Oliva de Los Andes Premium) with 0.2 wt\% of acidity was purchased from a local market and used as feedstock. Free liquid lipase from genetically modified Thermomyces lanuginosus microorganism (commercially named as Lipozyme TL 100L) with a nominal enzymatic activity of $100 \mathrm{LCLU} \cdot \mathrm{g}^{-1}$ and kindly provided by Novozymes Latin America LTDA (Araucária, Brazil) was used as biocatalyst. Glycerol and n-butanol (99.5\% purity, Alphatec, São Paulo, Brazil), Tween 80 PS surfactant (analytical grade, Dynamica, Indaiatuba, Brazil) were the chemicals used in the assays. Standards used in the HPLC analysis (SigmaAldrich, São Paulo, Brazil): linoleic acid (97 \% purity), oleic acid (> $99 \%$ purity), monopalmitic acid (> $99 \%$ purity), dilinoleic acid (98\% purity), glycerol trioleic (> $99 \%$ purity) and trilinoleic glycerol (98 \% purity). Acetonitrile (99.9 \% purity, Merck, São Paulo, Brazil) and acetone (99.8 \% Merck, São Paulo, Brazil) were used in the chromatographic analysis.

\section{Formation of Microemulsions}

Preliminary tests were performed to determine the volumetric ratios of feedstock, water and surfactant, where the follows glycerolysis to oil molar ratio was considered: $1: 1 ; 2: 1 ; 3: 1 ; 1: 2$ and 1:3, respecting a phase equilibrium diagram. After mixing the components of the microemulsion, it was subjected to constant stirring for 1.5 minutes in a Vortex homogenizer, and then stored at room temperature for 48 hours, according to the procedure described in Pescara [19]. 


\section{Enzymatic Glycerolysis and Factorial Design}

A Central Composite Rotatable Design (CCRD) plot with triplicate at the central point was used to determine the optimum conditions of MAG and DAG synthesis. Data analysis was performed using the software StatSoft Statistica, version 11.0. The effects of temperature and volumetric load of lipase on MAG and DAG yield were evaluated. The reactions were performed in a jacketed glass reactor, under constant stirring by mechanical stirrer (600 rpm) and temperature control. With the reaction parameters set, the enzyme was added and the enzymatic glycerolysis started for a period of 2 hours in $\mathrm{pH}$ 7.0. The values of the real and coded variables used in the statistical design are presented in Table 1. After the reaction, the enzyme separation was done by a system composed by a syringe filter, which was transferred to amber flasks brought into a Styrofoam container and then stored into the refrigerator. The filtration process was carried out to purify the sample. After separation, TAG, DAG, and MAG contents were determined by highperformance liquid chromatography.

Table 1. CCRD matrix, with real and coded values used in the reaction of glycerolysis catalyzed by Lipozyme TL 100L and conversions obtained to the TAG.

\begin{tabular}{c|c|c|c}
\hline Asssay & Temperature $\left({ }^{\circ} \mathbf{C}\right)$ & Enzyme Load $(\mathbf{v o l \%})$ & Conversion $(\%)$ \\
\hline 1 & $30(-1)$ & $5.0(-1)$ & 66.61 \\
2 & $40(+1)$ & $5.0(-1)$ & 70.24 \\
3 & $30(-1)$ & $10(+1)$ & 82.76 \\
4 & $40(+1)$ & $10(+1)$ & 86.72 \\
5 & $28(-1.41)$ & $7.5(0)$ & 72.79 \\
6 & $42(+1.41)$ & $7.5(0)$ & 58.28 \\
7 & $35(0)$ & $3.97(-1.41)$ & 67.73 \\
8 & $35(0)$ & $11.03(+1.41)$ & 97.11 \\
9 & $35(0)$ & $7.5(0)$ & 98.12 \\
\hline
\end{tabular}




\begin{tabular}{l|l|l|l}
\hline 10 & $35(0)$ & $7.5(0)$ & 98.82 \\
11 & $35(0)$ & $7.5(0)$ & 98.41 \\
\hline
\end{tabular}

127 Sample Analysis

128 High-performance liquid chromatography (HPLC, Thermo Scientific Ultimate 3000) was 129 used in the quantification of TAG, DAG MAG and FFA according procedure described by Lima 130 et al. [20]. Phenomenex C18 column of $5 \mu \mathrm{m}$ and $100 \AA$ (250 x $4.6 \mathrm{~mm}$, model 00G-4252-E0), 131 flow rate of $1.0 \mathrm{~mL} \cdot \mathrm{min}^{-1}$, column temperature of $35^{\circ} \mathrm{C}$ and detector temperature of $40{ }^{\circ} \mathrm{C}$ were 132 used in the analysis. The mobile phase was acetonitrile:acetone $\left(1: 1, \mathrm{v} \cdot \mathrm{v}^{-1}\right)$ and the injection volume 133 was $20 \mu \mathrm{L}$. The content of reaction products was expressed in terms of the whole amount of MAG, 134 DAG, TAG and FFA as weight percent of the total sample in surfactant-free basis.

\section{Kinetic Modeling}

The kinetics were determined in three different conditions, according preliminary tests 138 performed in terms of TAG conversion and presented on Table 2, where the effect of the water 139 content in the reaction was evaluated and the formation of MAG, DAG and FFA was monitored.

140 The system temperature, concentration of olive oil and lipase load was fixed for all the experiments 141 at $35^{\circ} \mathrm{C}, 10$ vol\% and 7.5 vol\% respectively. These amounts utilized were determined through tests 142 of formation and stabilization of the microemulsions. The amount of enzyme and temperature were 143 used based on the results obtained via statistical design. 
147 Table 2. Reaction conditions applied in the kinetics analysis of the system.

\begin{tabular}{c|c|c}
\hline Asssay & Glycerol (vol\%) & Water (vol\%) \\
\hline 1 & 7.40 & 5.0 \\
2 & 7.69 & 10.0 \\
3 & 8.00 & 15.0 \\
\hline
\end{tabular}

152 ternary model, Ping-Pong Bi-Bi and Ping-Pong-Bi complex for the glycerolysis of palm oil using 153 the enzyme Lipozyme TL IM in a solvent-free system. However, for all models, the hydrolysis 154 reactions were not considered, suggesting that the reactions were conducted under "micro155 aqueous" conditions. In this sense, this work presented the Ping-Pong Bi-Bi mathematical model 156 described by the set of equations - Eq. (1) to Eq (6), and also the hydrolysis reactions, characterized 157 by equations $\mathrm{Eq}(7)$ to $\mathrm{Eq}(10)$.

$$
\begin{aligned}
& T A G+E K_{1} \rightarrow K_{-1} \leftarrow E-T A G \\
& E-T A G K_{2} \rightarrow D A G+E-F F A \\
& E-F F A+G K_{3} \rightarrow K_{-3} \leftarrow E-F F A-G \\
& E-F F A-G K_{4} \rightarrow M A G+E \\
& D A G+E K_{5} \rightarrow K_{-5} \leftarrow E-D A G \\
& E-D A G K_{6} \rightarrow M A G+E-F F A \\
& E-T A G+W K_{7} \rightarrow K_{-7} \leftarrow D A G+F F A+E
\end{aligned}
$$




$$
\begin{gathered}
E-D A G+W K_{8} \rightarrow K_{-8} \leftarrow M A G+E+F F A \\
M A G+E K_{9} \rightarrow K_{-9} \leftarrow M A G-E \\
E-M A G K_{10} \rightarrow F F A+E+G
\end{gathered}
$$

161

162 From the elementary equations, the following kinetic equations can be written:

163

$$
\begin{aligned}
& r_{1}=-K_{1} C_{T A G}(t) C_{E}(t)+K_{-1} C_{T A G-E}(t) \\
& r_{2}=-K_{2} C_{T A G-E}(t) \\
& r_{3}=-K_{3} C_{E-F F A}(t) C_{G}(t)+K_{-3} C_{E-F F A-G}(t) \\
& r_{4}=-K_{4} C_{E-F F A-G}(t) \\
& r_{5}=-K_{5} C_{D A G}(t) C_{E}(t)+K_{-5} C_{E-D A G}(t) \\
& r_{6}=-K_{6} C_{E-D A G}(t) \\
& r_{7}=-K_{7} C_{E-T A G} C_{w}(t)+K_{-7} C_{D A G}(t) C_{F F A}(t) C_{E}(t) \\
& r_{8}=-K_{8} C_{E-D A G} C_{w}(t)+K_{-7} C_{M A G}(t) C_{F F A}(t) C_{E}(t) \\
& r_{9}=-K_{9} C_{M A G}(t) C_{E}(t)+K_{-9} C_{E-M A G}(t) \\
& r_{10}=-K_{10} C_{E-M A G}(t) C_{E}(t)+K_{-10} C_{F F A}(t) C_{E}(t) C_{G}(t)
\end{aligned}
$$
stoichiometry, was obtained the enzymatic kinetics model for the several species involved in the 167 mechanism of the glycerolysis reaction, described by the Equations (21) to (31):

$$
\begin{gathered}
\frac{d C_{T A G}}{d t}=r_{1} \\
\frac{d C_{D A G}}{d t}=-r_{2}+r_{5}-r_{7}
\end{gathered}
$$




$$
\begin{gathered}
\frac{d C_{M A G}}{d t}=-r_{4}-r_{6}-r_{8}+r_{9} \\
\frac{d C_{G}}{d t}=-r_{3}+r_{10} \\
\frac{d C_{E}}{d t}=r_{1}-r_{4}+r_{5}-r_{7}-r_{8}+r_{9}-r_{10} \\
\frac{d C_{E-T A G}}{d t}=-r_{1}+r_{2}+r_{7} \\
\frac{d C_{E-F F A}}{d t}=-r_{2}+r_{3}-r_{6} \\
\frac{d C_{E-F F A-G}}{d t}=-r_{3}+r_{4} \\
\frac{d C_{W}}{d t}=r_{7}+r_{8} \\
\frac{d C_{F F A}}{d t}=-r_{7}-r_{8}-r_{10} \\
\frac{d C_{M G-E}}{d t}=-r_{9}+r_{10}
\end{gathered}
$$

171 the total enzyme concentration remains constant, represented by the Equation (32):

172

$$
C_{E}(t=0)=C_{E}+C_{E-T A G}+C_{E-D A G}-C_{E-M A G}+C_{E-F F A}+C_{E-F F A-G}
$$

173

174

175 176 177 concentration are expressed in $\mathrm{g} . \mathrm{L}^{-1}$.
The initial conditions are given by Equations (33) to (44). All concentration values are expressed in mol. $\mathrm{kg}^{-1}$ and were calculated for each component based on the average molecular mass of olive oil, the mass of each element and total mass of oil and water. The enzyme

$$
\begin{gathered}
C_{T A G}(0)=C_{T A G, 0}{ }^{\exp } \\
C_{D A G}(0)=0
\end{gathered}
$$




$$
\begin{gathered}
C_{M A G}(0)=0 \\
C_{G}(0)=0 \\
C_{E}(0)=C_{E, 0} \exp \\
C_{E-T A G}(0)=0 \\
C_{E-F F A}(0)=0 \\
C_{E-F F A-G}(0)=0 \\
C_{W}(0)=C_{W, 0} \exp \\
C_{F F A}(0)=0 \\
C_{E-M A G}(0)=0 \\
C_{E-D A G}(0)=0
\end{gathered}
$$

\section{Parameter Estimation}

The mathematical model parameters $\left(\mathrm{K}_{1}, \mathrm{~K}_{-1}, \mathrm{~K}_{2}, \mathrm{~K}_{3}, \mathrm{~K}_{-3}, \mathrm{~K}_{4}, \mathrm{~K}_{5}, \mathrm{~K}_{-5}, \mathrm{~K}_{6}, \mathrm{~K}_{7}, \mathrm{~K}_{-7}, \mathrm{~K}_{8}, \mathrm{~K}_{-8}\right.$,

$182 \mathrm{~K}_{9}, \mathrm{~K}_{-9}, \mathrm{~K}_{10}$ e $\mathrm{K}_{-10}$ ) were estimated from the kinetics of the enzymatic hydrolysis of olive oil (TAG,

183 DAG, MAG and FFA) and minimization of the objective function represented by Equation (32).

184 The simplex Dowhill optimization method developed by Nelder and Mead [22] was used in the 185 pursuit of the objective function minimum.

186

$$
o b=\sum_{j=1}^{n c} \sum_{i=1}^{n d}\left(C_{j i}^{e x p}-C_{j i}^{m o d}\right)^{2}
$$

188 where $n c$ is the number of components (TAG, DAG, MAG and FFA); $n d$ is the number of 189 experimental data; $C_{j i}{ }^{\text {exp }}$ is the experimental concentration of component $j$ and; $C_{j i}{ }^{\text {mod }}$ is the 
component concentration $j$ calculated by the model;

192 particular initial conditions, Equations from (33) to (44) were used to model the behavior of the reaction system and to determine the kinetic parameters of the hydrolysis reactions of olive oil. For

194 the solution of the mathematical model, the numerical method of Rosenbrock [23] was used, using 195 the software Maple ${ }^{\circledR}$, version 13 (Waterloo Maple Inc., Canada).

\section{Results and Discussion}

\section{Central Composite Rotatable Design (CCRD)}

200 The conversion of TAG was in the range of $58 \%$ to $98 \%$. Table 3 presents the results of ANOVA 201 and Figure 1 the Pareto diagram.

202

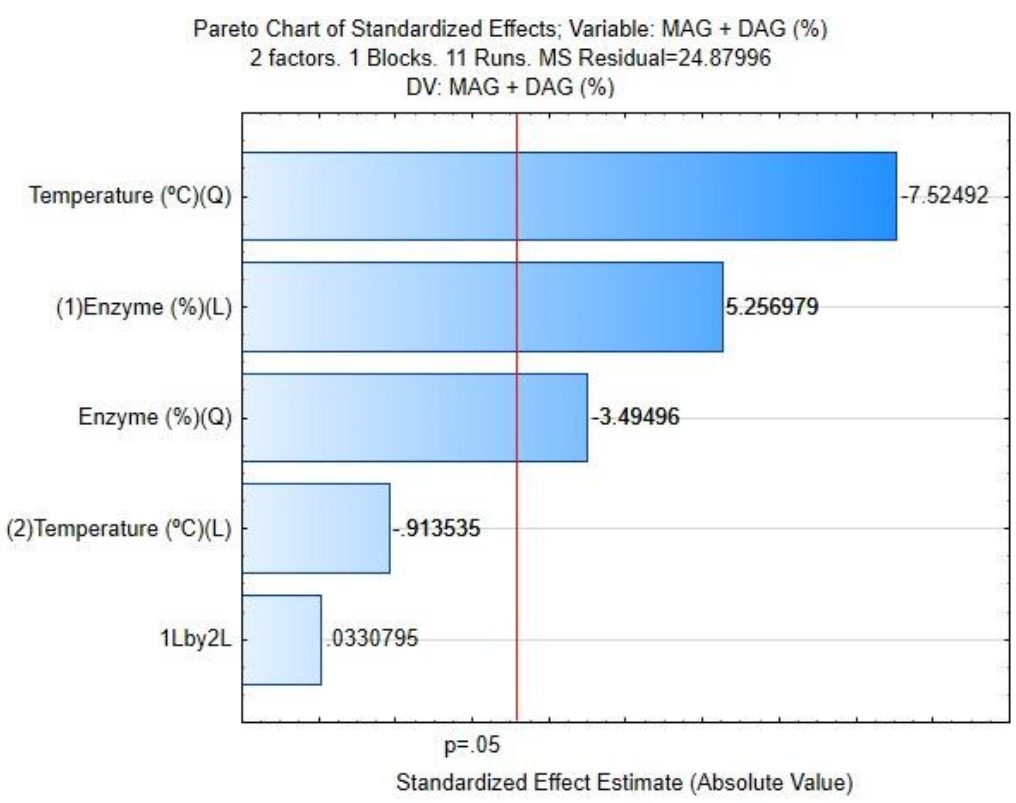

204 Figure 1. Pareto diagram obtained to the experiments performed. 
Table 3. Analysis of Variance (ANOVA) to the CCRD design.

206

\begin{tabular}{lccccc}
\hline \multicolumn{1}{c}{ Factor } & Sum of Squares & Degree of Freedom & Mean Square & F $_{\text {Calculated }}$ & $p$-value \\
\hline$(1)$ Enzyme Load (vol\%) (L) & 687.58 & 1 & 687.58 & 27.63 & $0.0033^{\mathrm{a}}$ \\
Enzyme Load (vol\%) (Q) & 303.90 & 1 & 303.90 & 12.21 & $0.0174^{\mathrm{a}}$ \\
$(2)$ Temperature $\left({ }^{\circ} \mathrm{C}\right)(\mathrm{L})$ & 20.76 & 1 & 20.76 & 0.83 & $0.4029^{\mathrm{b}}$ \\
Temperature $\left({ }^{\circ} \mathrm{C}\right)(\mathrm{Q})$ & $1,408.81$ & 1 & $1,408.81$ & 56.62 & $0.0007^{\mathrm{a}}$ \\
$1 \mathrm{~L}$ by 2L & 0.03 & 1 & 0.03 & $<0.01$ & $0.9749^{\mathrm{b}}$ \\
Error & 124.40 & 5 & 24.88 & & \\
\hline Total SS & $2,287.70$ & 10 & & & \\
\hline
\end{tabular}

a Significant at "Prob $>$ F" less than 0.05 ;

b Insignificant at "Prob $>$ F" more than 0.05 . 
Significant variables presented $\mathrm{p}<0.05$. Coefficients with a positive sign indicate a

211

212

213

214

215

216

217

218

219

220

221

222

223

224

225

226

227

228

229

230

231

232

233

synergic effect whereas negative coefficients indicate an antagonistic effect in the formation of MAG and DAG [24]. Moreover, the results presented show that any variation in the system significantly changes the conversion, statistically stating. This can be explained because an emulsion composes the system, and this emulsion needs balance and stability, which can be affected depending on the compound that is added to the medium. In turn, when using a lipase to promote the catalysis, a special attention must be given to parameter "reaction temperature", since the enzymes are a temperature sensitive protein. This implies that any value below its optimum temperature, the enzymatic activity could be considerably reduced and, mainly, above the optimal temperature, can occurs the protein denaturation and activation loss, which is irreversible, drastically affecting the process yield. Therefore, the knowledge of the "ideal" process conditions is fundamental. Since the process variables are kept in this "ideal" range so that the synthesis of MAG and DAG is maximum, increasing the reaction efficiency [25].

The results presented in the Table 1 and 3, and the Pareto diagram (Figure 1), shows an interactive effect between the variables "enzyme load" and "system temperature" and an independent analysis of the parameters would not be appropriate. Therefore, a contour surface between the parameters considered is necessary to find the region with the best response and thus determine the optimum conditions of the system, where the formation of MAG and DAG is maximum. These results can be observed in the Figure 2 in terms of volumetric concentration of enzyme. The data presented shows that the region of most significant conversion of the triglycerides that composed the feedstock used is close to the central point of the statistical design. In other words, the temperature is around $35{ }^{\circ} \mathrm{C}$ and the enzyme load between 7.5 to 9 vol\%. According previously discussed, temperatures above $40{ }^{\circ} \mathrm{C}$ hampered the raw material conversion since the catalytic capacity of the lipase was negatively affected due these high temperatures. On 
234 the other hand, temperatures below $30^{\circ} \mathrm{C}$ were not sufficient to activate the catalyst, also resulting 235 in low yields. Lower values of temperatures tend to cause a decrease of enzymatic activity, whereas 236 larger values can cause potential protein denaturation and in both, reduction of the activity occurs $237[26,27]$. Regarding the biocatalyst load, as expected, an increase in the lipase concentration used 238 in the medium returned an increase in the observed conversions. However, it is worth noting that 239 there was little difference in the TAG conversions when the lipase load increased from 7.5 vol\% 240 to $10 \mathrm{vol} \%$, making it more economically viable to adopt the value of 7.5 vol\% of Lipozyme TL 241100 as ideal. Is not difficult observe in situations when an excess of enzyme is used a formation of 242 agglomerates that resulting in a mass transfer resistance and consequently decreasing the 243 conversion. Thus, the best conditions obtained from the results presented is $35{ }^{\circ} \mathrm{C}, 7.5$ vol\% of 244 Lipozyme TL 100, a molar ratio of 2:1 (glycerolysis:oil) at $600 \mathrm{rpm}$ rate and $2 \mathrm{~h}$ of reaction, 245 resulting in an average conversion of $98.5 \%$.

246 The results found for the best conditions are in agreement with the study published by 247 Raizer [28]. This study synthesized DAG by enzymatic glycerolysis from sunflower oil by 248 ultrasound assistance and used a CCRD with temperature and amount of enzyme as independent 249 variables. Through ANOVA and Pareto Diagram, the author concluded that the most significant 250 variable was the enzyme load.

251 

DV: MAG + DAG (\%)

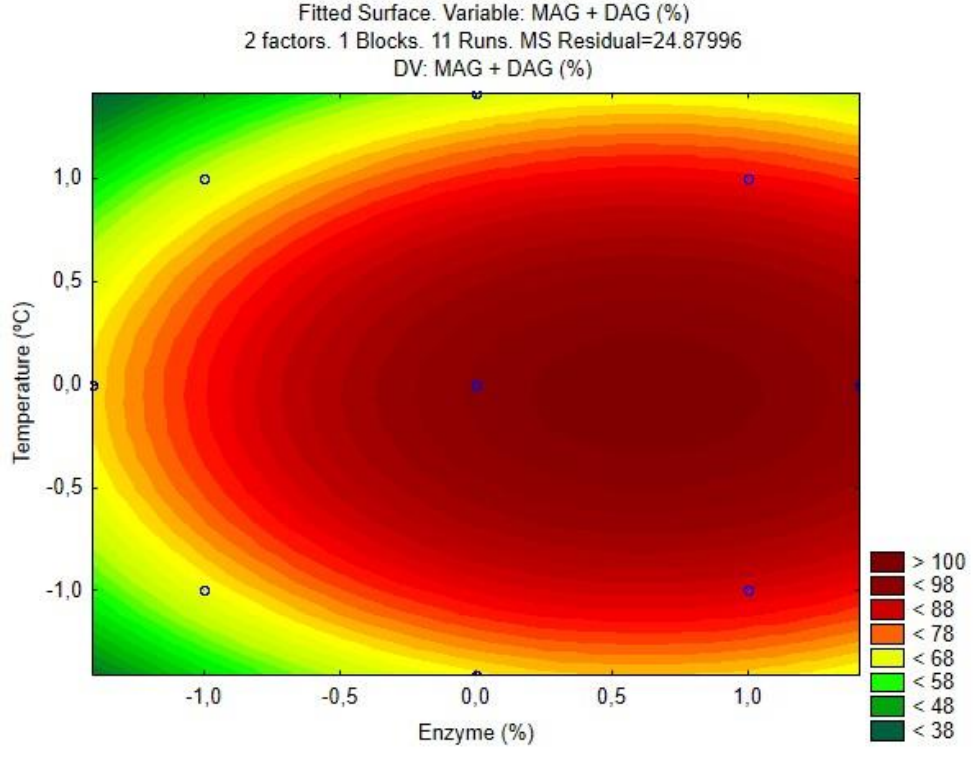

253 Figure 2. Contour surface for TAG conversion varying temperature and biocatalyst load.

\section{Mathematical Modeling}

The kinetic constants were initially estimated using 7.5 vol\% of the Lipozyme TL 100 enzyme and assuming the hypothesis of having a reaction coefficient as an independent factor in the medium. Such parameter is important since the use of excess enzyme may result in enzyme aggregation, which ends up exposing the active site of the enzyme to substrate molecules and thus, the model would not be efficient and would have to reformulate the conditions of analysis. The

261 values of the estimated parameters obtained to the model are presented in Table 4. The results of 262 the simulations are presented in Figures 3 to 5. It is possible to observe that the proposed model 263 appropriately represented the kinetics of glycerolysis of olive oil. 
265 Table 4. Estimated kinetic reaction constants.

266

\begin{tabular}{|c|c|c|c|c|c|c|}
\hline Parameter & $\begin{array}{c}\mathrm{K}_{1} \\
\left(\mathrm{~L} \cdot \mathrm{mol}^{-1} \cdot \min ^{-1}\right)\end{array}$ & $\underset{\left(\mathrm{min}^{-1}\right)}{\mathrm{K}_{-1}}$ & $\underset{\left(\min ^{-1}\right)}{\mathrm{K}_{2}}$ & $\begin{array}{c}\mathrm{K}_{3} \\
\left(\mathrm{~L} \cdot \mathrm{mol}^{-1} \cdot \min ^{-1}\right)\end{array}$ & $\begin{array}{c}\mathrm{K}_{-3} \\
\left(\mathrm{~min}^{-1}\right)\end{array}$ & $\begin{array}{c}\mathrm{K}_{4} \\
\left(\mathrm{~min}^{-1}\right)\end{array}$ \\
\hline Estimated Value & 13.76 & 181.99 & 53.27 & $1.108 \cdot 10^{4}$ & $8.179 \cdot 10^{3}$ & $2.725 \cdot 10^{3}$ \\
\hline Parameter & $\begin{array}{c}\mathrm{K}_{5} \\
\left(\mathrm{~L} \cdot \mathrm{mol}^{-1} \cdot \min ^{-1}\right)\end{array}$ & $\begin{array}{c}\mathrm{K}-5 \\
\left(\mathrm{~min}^{-1}\right)\end{array}$ & $\begin{array}{c}\mathrm{K}_{6} \\
\left(\mathrm{~min}^{-1}\right)\end{array}$ & $\begin{array}{c}\mathrm{K}_{7} \\
\left(\mathrm{~L} \cdot \mathrm{mol}^{-1} \cdot \min ^{-1}\right)\end{array}$ & $\begin{array}{c}\mathrm{K}_{-7} \\
\left(\mathrm{~L}^{2} \cdot \mathrm{g}^{-1} \cdot \mathrm{mol}^{-1} \cdot \mathrm{min}^{-1}\right)\end{array}$ & $\begin{array}{c}\mathrm{K}_{8} \\
\left(\mathrm{~L} \cdot \mathrm{mol}^{-1} \cdot \min ^{-1}\right)\end{array}$ \\
\hline Estimated Value & 3.47 & 90.21 & 7.33 & 37.44 & 1.83 & 1.90 \\
\hline Parameter & $\begin{array}{c}\mathrm{K}_{-8} \\
\left(\mathrm{~L}^{2} \cdot \mathrm{g}^{-1} \mathrm{~mol}^{-1} \cdot \mathrm{min}^{-1}\right)\end{array}$ & $\begin{array}{c}\mathrm{K}_{9} \\
\left(\mathrm{~L} \cdot \mathrm{mol}^{-1} \cdot \min ^{-1}\right)\end{array}$ & $\begin{array}{c}\mathrm{K}_{-9} \\
\left(\mathrm{~L}^{2} \cdot \mathrm{g}^{-1} \mathrm{~mol}^{-1} \cdot \mathrm{min}^{-1}\right)\end{array}$ & $\begin{array}{c}\mathrm{K}_{10} \\
\left(\mathrm{~L} \cdot \mathrm{mol}^{-1} 1 \cdot \min ^{-1}\right)\end{array}$ & $\begin{array}{c}\mathrm{K}_{-10} \\
\left(\mathrm{~L}^{2} \cdot \mathrm{g}^{-1} \mathrm{~mol}^{-1} \cdot \mathrm{min}^{-1}\right)\end{array}$ & \\
\hline Estimated Value & 0.50 & 23.49 & 145.92 & 65.26 & 7.04 & \\
\hline
\end{tabular}




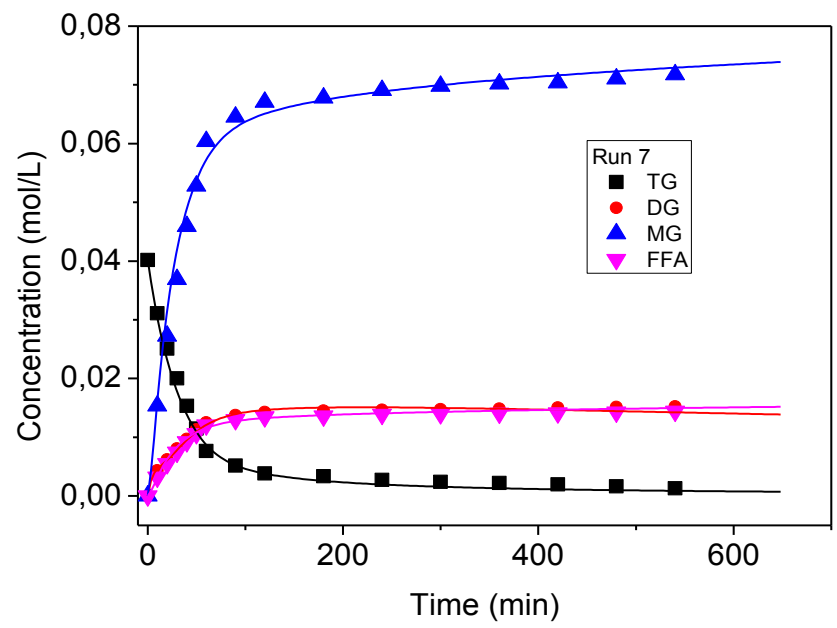

269

270 Figure 3. Kinetics of glycerolysis of olive oil. Reaction conditions: $35^{\circ} \mathrm{C}, 7.4 \%$ of glycerol, 10 271 vol\% of olive oil, 5 vol\% of water and $7.5 \mathrm{vol} \%$ enzyme.

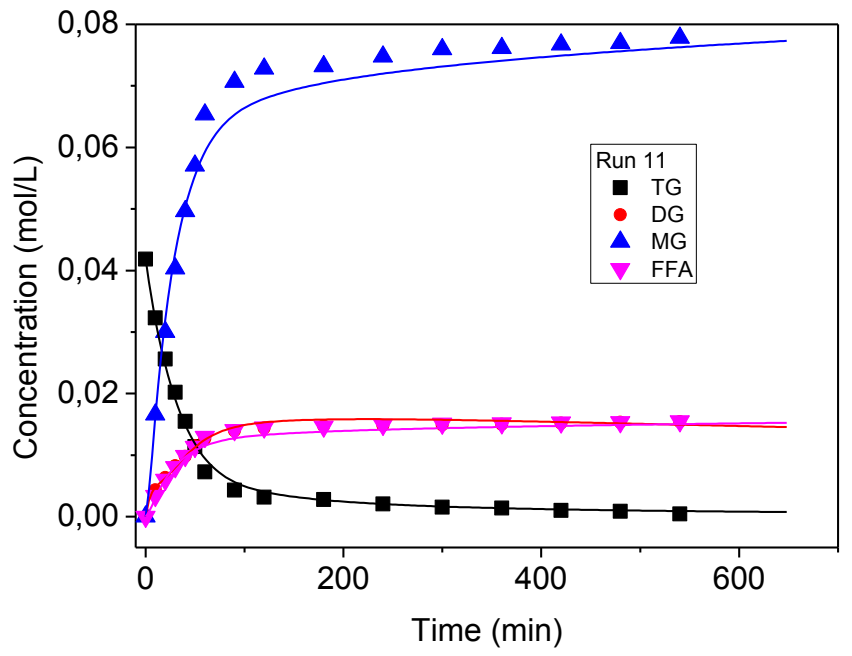

274 Figure 4. Kinetics of glycerolysis of olive oil. Reaction conditions: $35^{\circ} \mathrm{C}, 7.69 \%$ of glycerol, 10 275 vol\% of olive oil, 10 vol\% of water and 7.5 vol\% of enzyme. 


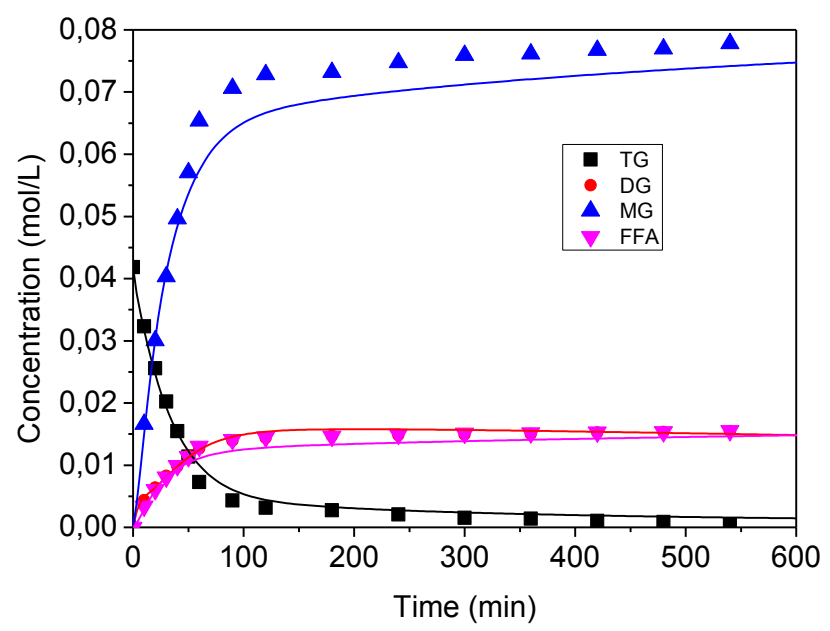

277

278 Figure 5. Kinetics of glycerolysis of olive oil. Reaction conditions: $35^{\circ} \mathrm{C}, 8.0 \%$ of glycerol, 10

279 vol\% of olive oil, 15 of vol\% of water and 7.5 vol \% of enzyme.
Experimental kinetics data show that the concentration of TAG had a significant reduction between 0 and 120 minutes, indicating that the amount of enzyme used was adequate to promote the reaction. In the same way, it is verified that the higher production of MAG and DAG was in this period of time since such products are formed from the decomposition of the TAG. This was also observed by Corzo-Martínez et al. [29] and Fiametti [30] that the higher formation of MAG and DAG occurred within the first 120 minutes of reaction. It was also noted that the formation of MAG was much higher than that of DAG, but both stabilized at similar times, which indicates another sign that the amount of enzyme was sufficient in the process.

This model of curves is characteristic in TAG hydrolysis reactions, even with different matrices. In the work of Solaesa et al. [25], the authors performed enzymatic glycerolysis tests on several systems with sardine oil as a source of TAG. As such, they analyzed levels of MAG and DAG in micellar systems and catalyzed by the enzyme Lipozyme 435. Comparing all the kinetic curves of the TAG, MAG, DAG and FFA compounds, it is seen that there is the same pattern of 
294 formation, with more considerable amounts of MAG formation, followed by DAG and, finally, 295 FFA.

296 When analyzing the water fraction in the reaction medium, it did not present significant 297 differences, since the limiting factors for the process were the amount of enzyme and temperature 298 of the system. According studies conducted by Irimescu et. al [31] and Yang et. al [32] 299 microemulsions with several enzymes were tested, among them lipases, immobilized or not, and 300 achieved significant TAG conversion rates, and the amount of water was also crucial for the 301 stabilization of the system micellar. On the other hand, in the work of Moya-Ramírez et al. [33], 302 the authors obtained MAG and DAG from used frying oil and the reaction of glycerolysis with the 303 use of several enzymes was strongly dependent on the amount of water inside the micellar system 304 and the conditions with higher enzyme concentrations, better results were obtained. However, the 305 conversion range of triglycerides was in the range of $30 \%$ inferior, relatively low when compared 306 to the present study. This may have occurred due to the raw material used by the authors (used 307 frying oil) contains several impurities and contaminants due to the breakage and oxidation that the 308 oil had undergone.

Another critical parameter in the glycerolysis reaction is the formation of a stable micellar system. The high conversions of consumption of triglycerides show that this happened in the cases

311 studied. All the results obtained can be tested, for example, in the automotive lubricant industries, 312 as an alternative emulsifier between base oil and performance additives. 


\section{Conclusions}

317 In this work, the enzymatic glycerolysis reaction of olive oil was investigated using

318 glycerolysis catalyzed by the commercial liquid enzyme Lypozyme TL 100L. The results of the

319 experimental design showed that the amount of enzyme used and the temperature of the system 320 were significant variables in the conversion of triglyceride. The experimental condition of $35^{\circ} \mathrm{C}$,

3217.5 vol\% of Lipozyme TL 100 enzyme, 2:1 molar ratio (glycerolysis:oil) and reaction time of 2 322 hours was the highest conversion of triglycerides (98.45\%). The mathematical model that 323 considers the reaction mechanism of Ping Pong Bi Bi type and hydrolysis reactions proved to be 324 efficient to describe reaction kinetics and can be an essential tool for reactor projects that operate 325 at larger scales.

326

327 Declarations

328 - Ethical Approval: This article does not contain any studies with human participants or animals 329 performed by any of the authors.

330 - Consent to Participate: All authors have consented to participate in the paper.

331 - Consent to Publish: All authors have consented to publish the paper.

332 - Authors Contributions:

333 George F. Finco: experimental data collection

334 Karina G. Fiametti: laboratory assays execution

335 Edson A. da Silva: experimental design and modeling

336 Fernando Palú: experimental data execution

337 João H. C. Wancura: manuscript writing and discussion

338 Alexsandra Valério: research planning 
J. Vladimir Oliveira: overall research planning, writing the manuscript

340 - Funding: No funding, not applicable.

341 - Competing Interests: There is no conflict or competing interest.

342 - Availability of data and materials: Not applicable.

343

344 References

345 1. Hares Júnior, S. J., Ract, J. N. R., Gioielli, L. A., \& Vitolo, M. (2018). Conversion of 346 Triolein Into Mono- and Diacylglycerols by Immobilized Lipase. Arabian Journal for 347 Science and Engineering, 43(5), 2247-2255. https://doi.org/10.1007/s13369-017-2635-7

348 2. Lo, S.-K., Tan, C.-P., Long, K., Yusoff, M. S. A., \& Lai, O.-M. (2008). Diacylglycerol 349 350 351 1(3), 223. https://doi.org/10.1007/s11947-007-0049-3

3. Binhayeeding, N., Klomklao, S., \& Sangkharak, K. (2017). Utilization of Waste Glycerol from Biodiesel Process as a Substrate for Mono-, Di-, and Triacylglycerol Production. Energy Procedia, 138, 895-900. https://doi.org/10.1016/j.egypro.2017.10.130

4. Cao, X., Mangas-Sánchez, J., Feng, F., \& Adlercreutz, P. (2016). Acyl migration in enzymatic interesterification of triacylglycerols: Effects of lipases from Thermomyces lanuginosus and Rhizopus oryzae, support material, and water activity. European Journal of Lipid Science and Technology, 118(10), 1579-1587. https://doi.org/10.1002/ejlt.201500485

5. Ferretti, C. A., Spotti, M. L., \& Di Cosimo, J. I. (2018). Diglyceride-rich oils from glycerolysis of edible vegetable oils. Catalysis Today, 302, 233-241. https://doi.org/10.1016/j.cattod.2017.04.008

6. Jiang, W., Wang, S., Wang, Y., \& Fang, B. (2016). Key enzymes catalyzing glycerol to 1,3-propanediol. Biotechnology for Biofuels, 9(1), 57. https://doi.org/10.1186/s13068-0160473-6

7. Valério, A., Rovani, S., Treichel, H., de Oliveira, D., \& Oliveira, J. V. (2010). Optimization of mono and diacylglycerols production from enzymatic glycerolysis in solvent-free systems. Bioprocess and Biosystems Engineering, 33(7), 805-812. 
https://doi.org/10.1007/s00449-009-0402-1

8. Goswami, D. (2020). Lipase Catalysis in Presence of Nonionic Surfactants. Applied Biochemistry and Biotechnology, 191(2), 744-762. https://doi.org/10.1007/s12010-01903212-W

9. Hu, D.-J., Chen, J.-M., \& Xia, Y.-M. (2013). A comparative study on production of middle chain diacylglycerol through enzymatic esterification and glycerolysis. Journal of Industrial and Engineering Chemistry, 19(5), 1457-1463. https://doi.org/https://doi.org/10.1016/j.jiec.2013.01.009

10. Arranz-Martínez, P., Corzo-Martínez, M., Vázquez, L., Reglero, G., \& Torres, C. F. (2018). Lipase catalyzed glycerolysis of ratfish liver oil at stirred tank basket reactor: A kinetic approach. Process Biochemistry, 64, 38-45. https://doi.org/10.1016/j.procbio.2017.09.026

11. Odaneth, A. A., Vadgama, R. N., Bhat, A. D., \& Lali, A. M. (2016). Tuning Lipase Reaction for Production of Fatty Acids from Oil. Applied Biochemistry and Biotechnology, 180(3), 504-515. https://doi.org/10.1007/s12010-016-2113-9

12. Song, Z., Liu, Y., Jin, Q., Li, L., Wang, X., Huang, J., \& Liu, R. (2012). Lipase-Catalyzed Preparation of Diacylglycerol-Enriched Oil from High-Acid Rice Bran Oil in Solvent-Free System. Applied Biochemistry and Biotechnology, 168(2), 364-374. https://doi.org/10.1007/s12010-012-9780-y

13. Larissa Freitas, Victor H. Perez, Julio C. Santos, \& Heizir F. de Castro. (2007). Enzymatic synthesis of glyceride esters in solvent-free system: influence of the molar ratio, lipase source and functional activating agent of the support. Journal of the Brazilian Chemical Society, 18(7), 1360-1366. https://doi.org/10.1590/S0103-50532007000700011

14. Fregolente, P. B. L., Fregolente, L. V., Pinto, G. M. F., Batistella, B. C., Wolf-Maciel, M. R., \& Filho, R. M. (2008). Monoglycerides and Diglycerides Synthesis in a Solvent-Free System by Lipase-Catalyzed Glycerolysis. Applied Biochemistry and Biotechnology, 146(1), 165-172. https://doi.org/10.1007/s12010-008-8133-3

15. C. Wancura, J. H., Tres, M. V., Jahn, S. L., \& Oliveira, J. V. (2020). Lipases in liquid formulation for biodiesel production: Current status and challenges. Biotechnology and Applied Biochemistry, 67(4), 648-667. https://doi.org/10.1002/bab.1835

16. Jesus, J., Santana, P., \& Silva, F. V. (2013). Different Approaches in Concentration- 
Temperature Cascade Control of a Fixed Bed Reactor for the Phthalic Anhydride Synthesis. Chemical Engineering Transactions, 32, 1387-1392. https://doi.org/10.3303/CET1332232

17. Cabral, P. S., Filho, A. Z., Voll, F. A. P., \& Corazza, M. L. (2014). Kinetics of Enzymatic Hydrolysis of Olive Oil in Batch and Fed-batch Systems. Applied Biochemistry and Biotechnology, 173(6), 1336-1348. https://doi.org/10.1007/s12010-014-0943-x

18. Amaral, G. M., \& Giudici, R. (2011). Kinetics and Modeling of Fatty Alcohol Ethoxylation in an Industrial Spray Loop Reactor. Chemical Engineering \& Technology, 34(10), 1635-1644. https://doi.org/10.1002/ceat.201100215

19. Pescara, P. M. (2016). Study of the formation of microemulsions of water in olive oils. Retrieved from http://repositorio.roca.utfpr.edu.br/jspui/handle/1/16690

20. de Lima, A. P. D., Aschenbrenner, E. M., Oliveira, S. do N., Doucet, J.-B., Weiss, C. K., Ziener, U., Landfester, K. (2013). Towards regioselective enzymatic hydrolysis and glycerolysis of tricaprylin in miniemulsion and the direct preparation of polyurethane from the hydrolysis products. Journal of Molecular Catalysis B: Enzymatic, 98, 127-137. https://doi.org/10.1016/j.molcatb.2013.10.013

21. Choong, T. S. Y., Yeoh, C. M., Phuah, E.-T., Siew, W.-L., Lee, Y.-Y., Tang, T.-K., \& Chuah Abdullah, L. (2018). Kinetic study of lipase-catalyzed glycerolysis of palm olein using Lipozyme TLIM in solvent-free system. PLOS ONE, 13(2), e0192375. https://doi.org/10.1371/journal.pone.0192375

22. Nelder, J. A., \& Mead, R. (1965). A Simplex Method for Function Minimization. The Computer Journal, 7(4), 308-313. https://doi.org/10.1093/comjn1/7.4.308

23. Rosenbrock, H. H. (1963). Some general implicit processes for the numerical solution of differential equations. The Computer Journal, 5(4), 329-330.

https://doi.org/10.1093/comjn1/5.4.329

24. Monte Blanco, S. F. M., Santos, J. S., Feltes, M. M. C., Dors, G., Licodiedoff, S., Lerin, L. A., Furigo, A. (2015). Optimization of diacylglycerol production by glycerolysis of fish oil catalyzed by Lipozyme TL IM with Tween 65. Bioprocess and Biosystems Engineering, 38(12), 2379-2388. https://doi.org/10.1007/s00449-015-1473-9

25. Solaesa, Á. G., Sanz, M. T., Melgosa, R., \& Beltrán, S. (2017). Substrates emulsification process to improve lipase-catalyzed sardine oil glycerolysis in different systems. 
Evaluation of lipid oxidation of the reaction products. Food Research International, 100, 572-578. https://doi.org/https://doi.org/10.1016/j.foodres.2017.07.048

26. Tu, Q., Lu, M., \& Knothe, G. (2017). Glycerolysis with crude glycerin as an alternative pretreatment for biodiesel production from grease trap waste: Parametric study and energy analysis. Journal of Cleaner Production, 162, 504-511. https://doi.org/10.1016/j.jclepro.2017.06.064

27. Correia, A. C. V. B., Fonseca, M. M. R., \& Ferreira-Dias, M. S. L. (2011). Production of emulsifiers through the glycerolysis of olive-pomace oil catalyzed by Candida rugosa lipase immobilized in polyurethane foams. Millenium, 41, 7-15. Retrieved from https://revistas.rcaap.pt/millenium/article/view/8204

28. Raizer, E. (2015). Use of ultrasound in diacylglycerol synthesis via enzymatic hydrolysis of sunflower oil. Western State University of Paraná. Retrieved from http://tede.unioeste.br:8080/tede/handle/tede/1861

29. Corzo-Martínez, M., Vázquez, L., Arranz-Martínez, P., Menéndez, N., Reglero, G., \& Torres, C. F. (2016). Production of a bioactive lipid-based delivery system from ratfish liver oil by enzymatic glycerolysis. Food and Bioproducts Processing, 100, 311-322. https://doi.org/10.1016/j.fbp.2016.08.003

30. Fiametti, K. G., Rovani, S., de Oliveira, D., Corazza, M. L., Treichel, H., \& Oliveira, J. V. (2009). Kinetics of Solvent-Free Lipase-Catalyzed Production of Monoacylglycerols from Olive Oil in Aerosol-OT Surfactant. Industrial \& Engineering Chemistry Research, 48(2), 708-712. https://doi.org/10.1021/ie8013956

31. Irimescu, R., Iwasaki, Y., \& Hou, C. T. (2002). Study of TAG ethanolysis to 2-MAG by immobilized Candida antarctica lipase and synthesis of symmetrically structured TAG. Journal of the American Oil Chemists' Society, 79(9), 879-883. https://doi.org/10.1007/s11746-002-0573-8

32. Yang, B., James Harper, W., Parkin, K. L., \& Chen, J. (1994). Screening of commercial lipases for production of mono- and diacylglycerols from butteroil by enzymic glycerolysis. International Dairy Journal, 4(1), 1-13. https://doi.org/10.1016/09586946(94)90045-0

33. Moya-Ramírez, I., García-Román, M., \& Fernández-Arteaga, A. (2016). Waste Frying Oil Hydrolysis in a Reverse Micellar System. ACS Sustainable Chemistry \& Engineering, 
461

4(3), 1025-1031. https://doi.org/10.1021/acssuschemeng.5b01118

462

463 


\section{List of Figure Captions}

465

466 Figure 1. Pareto diagram obtained to the experiments performed.

467

468 Figure 2. Contour surface for TAG conversion varying temperature and biocatalyst load.

469

470 Figure 3. Kinetics of glycerolysis of olive oil. Reaction conditions: $35^{\circ} \mathrm{C}, 7.4$ vol\% of glycerol,

$471 \quad 10$ vol\% of olive oil, 5 vol\% of water and $7.5 \mathrm{vol} \%$ enzyme.

472

473 Figure 4. Kinetics of glycerolysis of olive oil. Reaction conditions: $35^{\circ} \mathrm{C}, 7.69$ vol\% of glycerol, 47410 vol\% of olive oil, 10 vol\% of water and 7.5 vol\% of enzyme.

475

476 Figure 5. Kinetics of glycerolysis of olive oil. Reaction conditions: $35^{\circ} \mathrm{C}, 8.0$ vol\% of glycerol, 47710 vol\% of olive oil, 15 of vol\% of water and 7.5 vol \% of enzyme.

478 
481 Table 1. CCRD matrix, with real and coded values used in the reaction of glycerolysis catalyzed

482 by Lipozyme TL 100L and conversions obtained to the TAG.

483

484 Table 2. Reaction conditions applied in the kinectics analysis of the system.

485

486 Table 3. Analysis of Variance (ANOVA) to the CCRD design.

487

488 Table 4. Estimated kinetic reaction constants. 
Figures

Pareto Chart of Standardized Effects; Variable: MAG + DAG (\%)

2 factors. 1 Blocks. 11 Runs. MS Residual=24.87996

DV: MAG + DAG (\%)

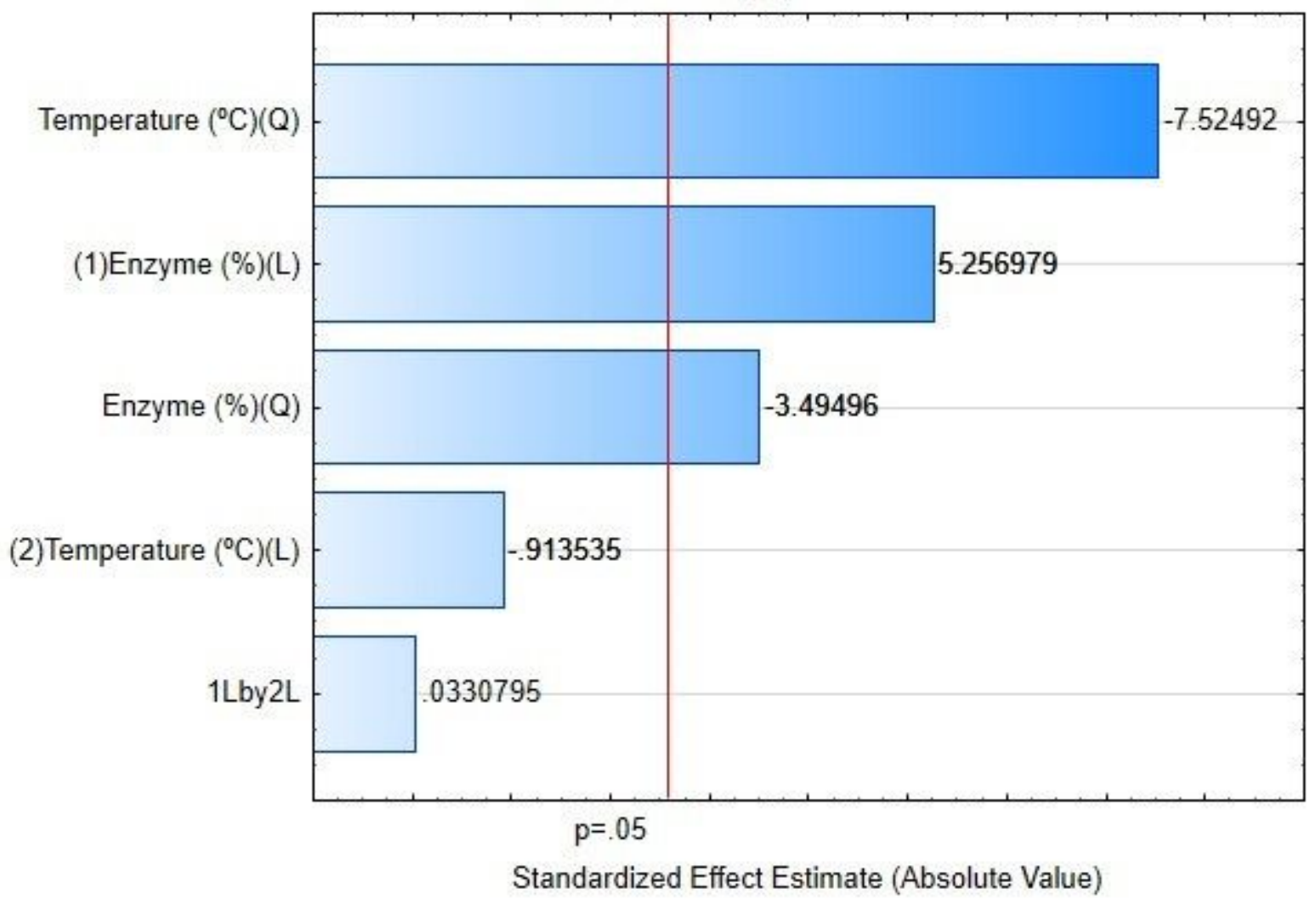

Figure 1

Pareto diagram obtained to the experiments performed. 
Fitted Surface. Variable: MAG + DAG (\%)

2 factors. 1 Blocks. 11 Runs. MS Residual=24.87996

DV: MAG + DAG (\%)

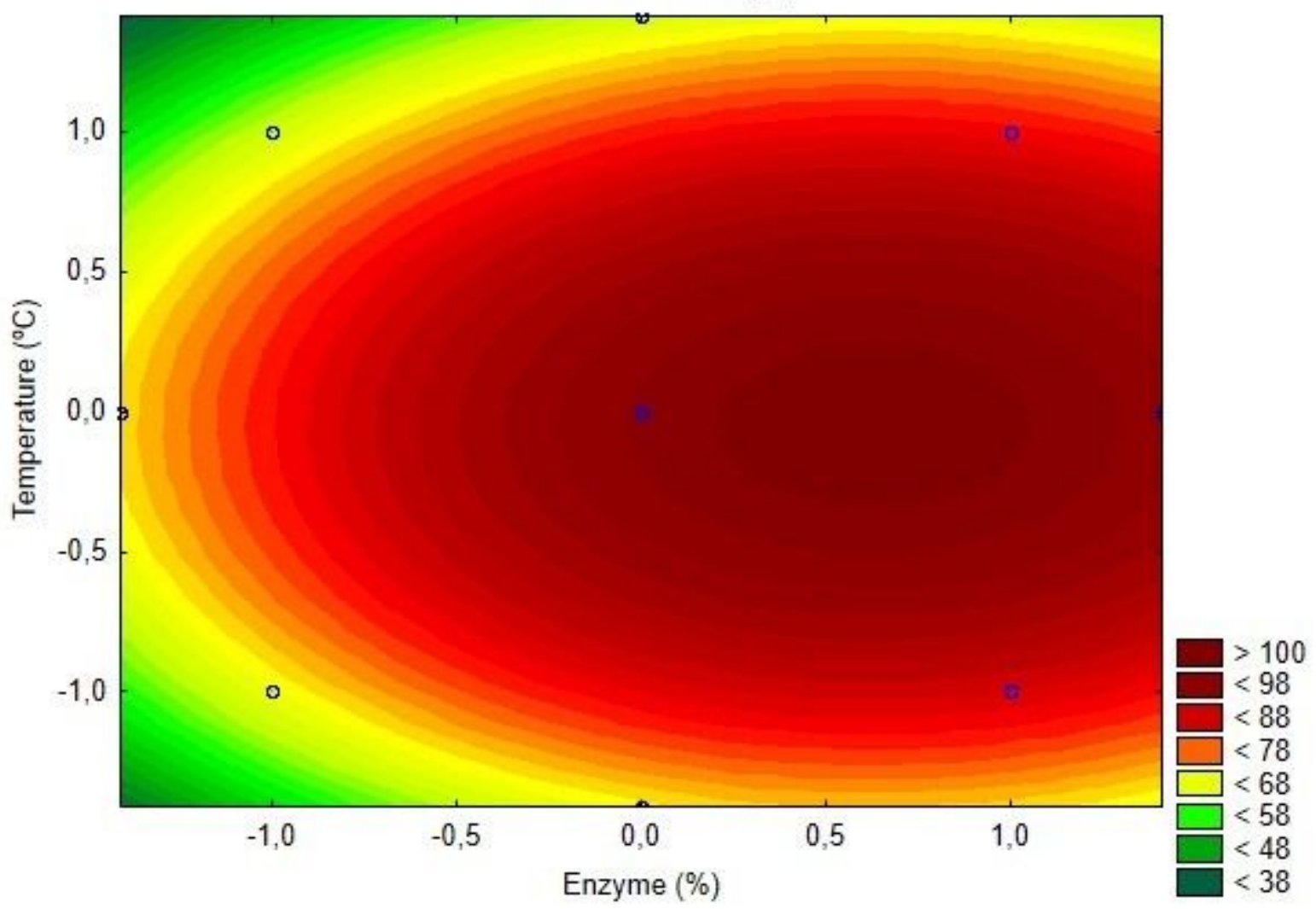

Figure 2

Contour surface for TAG conversion varying temperature and biocatalyst load. 


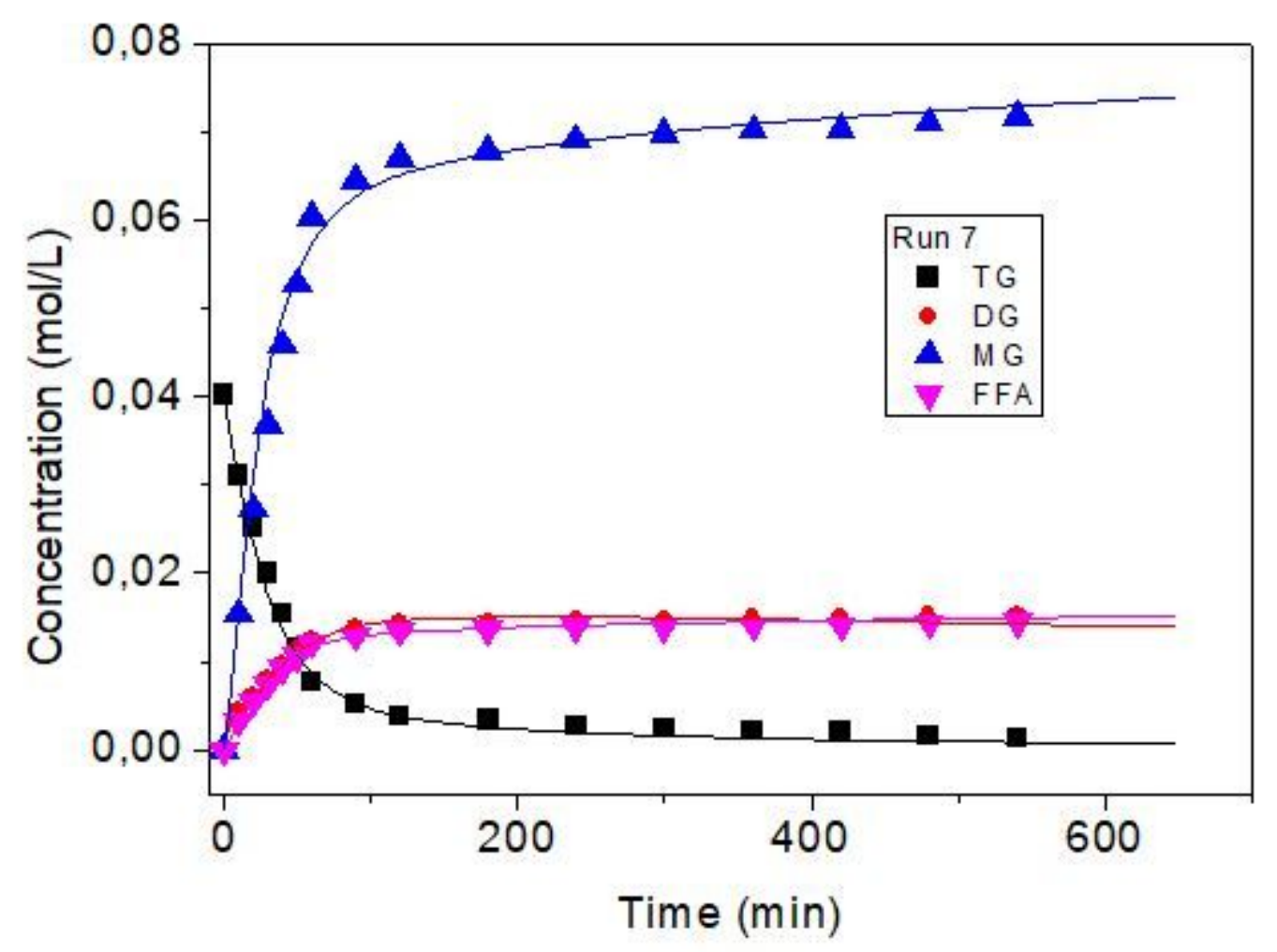

Figure 3

Kinetics of glycerolysis of olive oil. Reaction conditions: $35^{\circ} \mathrm{C}, 7.4$ vol\% of glycerol, 10 vol\% of olive oil, 5 vol\% of water and $7.5 \mathrm{vol} \%$ enzyme. 


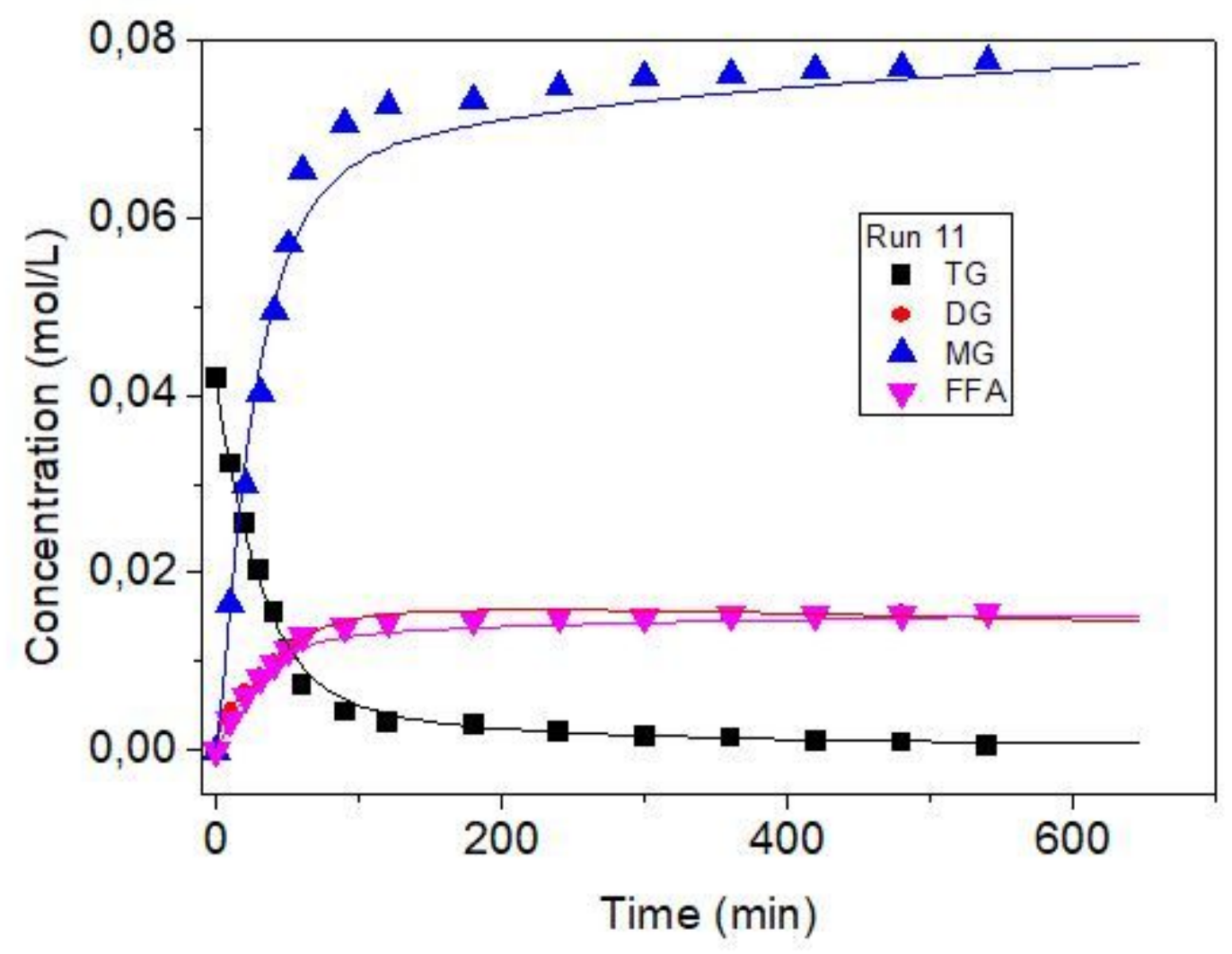

Figure 4

Kinetics of glycerolysis of olive oil. Reaction conditions: $35^{\circ} \mathrm{C}, 7.69 \mathrm{vol} \%$ of glycerol, $10 \mathrm{vol} \%$ of olive oil, 10 vol\% of water and 7.5 vol\% of enzyme. 


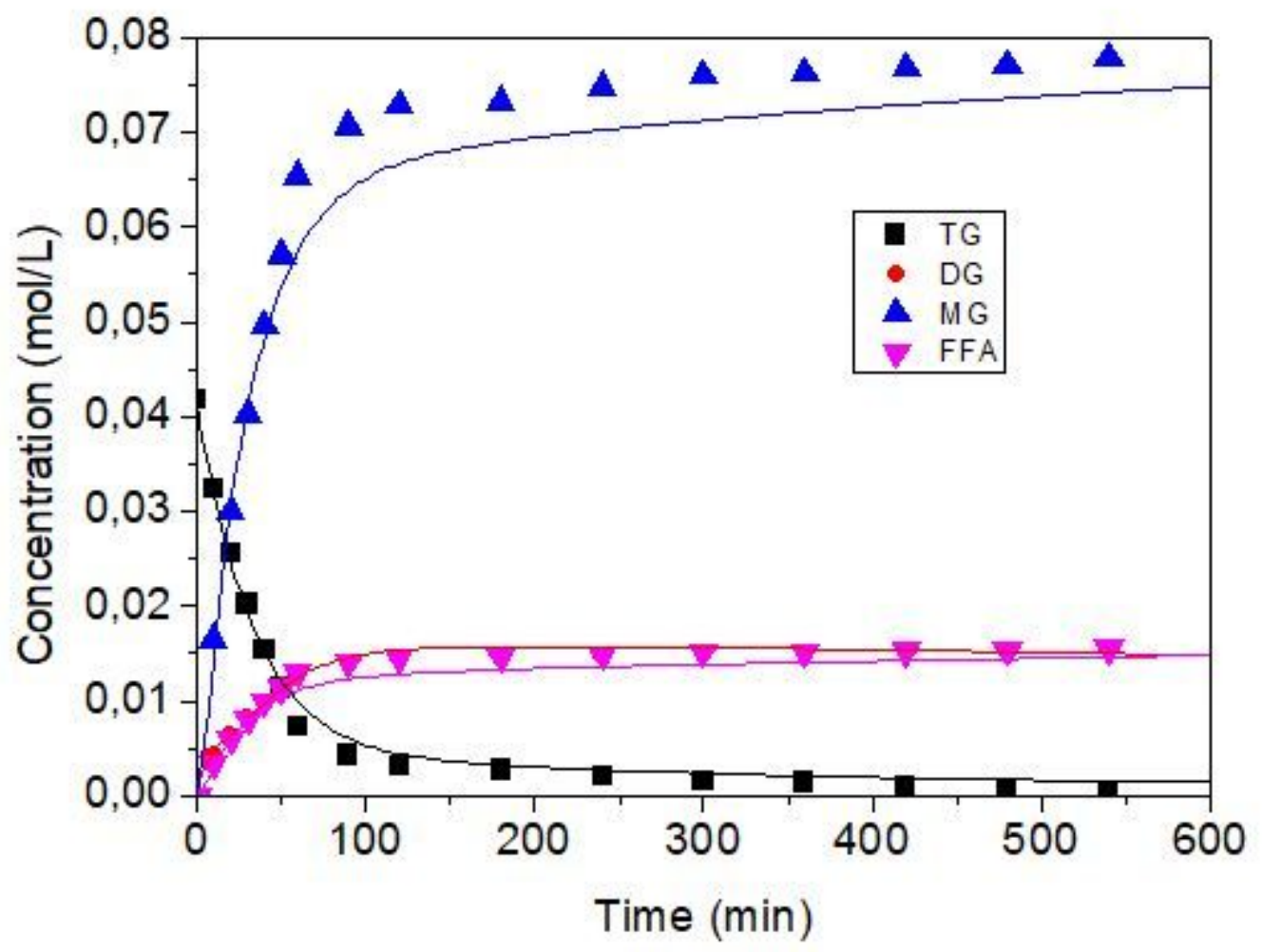

Figure 5

Kinetics of glycerolysis of olive oil. Reaction conditions: $35^{\circ} \mathrm{C}, 8.0$ vol\% of glycerol, 10 vol\% of olive oil, 15 of vol\% of water and $7.5 \mathrm{vol} \%$ of enzyme. 